\title{
Beyond supply and demand: addressing the complexities of workforce exclusion in Australia
}

\section{Ian Goodwin-Smith}

Flinders University

\section{Claire L. Hutchinson}

Flinders University

\section{Abstract}

Workforce exclusion is a complex and enduring problem in Australia, with some groups of job seekers more likely to be disadvantaged in the labour market than others. We identify a dominant 'work first' unemployment intervention narrative that ignores the nature of disadvantage and its relationship to workforce exclusion. This narrative reduces unemployment to a simple matter of labour market supply and demand, and privileges immediate economic productivity and exit from welfare payments over sustainable attachment to quality jobs. We examine fourteen programs for disadvantaged job seekers under one national provider network. Data was gathered from eleven semi-structured telephone interviews and eight evaluation reports and analysed using thematic analysis supported by NVivo. Our findings challenge the dominant narrative and stress the importance of a partnershiporientated and capacity building focus on the unemployed person, and the significance of quality employment with long term support. We identify the importance of acknowledging job seekers' strengths, aspirations and preferences, and of job seekers having agency to determine their own pathways with support from service providers.

Keywords: Workforce exclusion, disadvantaged job seekers, unemployment, 
employment support, job seeker training

\section{Introduction}

Workforce exclusion is a complex and enduring problem. Australia's unemployment rate is currently 6.3 per cent nationally, but the youth unemployment rate sits at approximately twice this figure (ABS, 2015). Long-term unemployment among youth has more than tripled since 2008 (Brotherhood of St. Lawrence, 2014). Whilst longterm and youth unemployment figures are rising, they are doing so at a rate which represents a historically normal relationship to the national unemployment rate (Borland, 2014), which indicates a need for policy attention above macroeconomic interventions designed to bring headline unemployment figures down. In the 2014 federal budget, Treasurer Joe Hockey declared a policy plan for addressing youth unemployment by imposing 'earn or learn' obligations on young job seekers in particular, as well as a six month waiting period for claiming welfare benefits for those under 30 years of age (Department of Human Services, 2014).

In post-budget media, Senator Eric Abetz, Minister for Employment, labelled youth unemployment a 'scourge' and suggested that those who shirk the opportunity of 'work for the dole' do not deserve welfare payments (Abetz, 2014a). In so doing, he implied that only some unemployed people are deserving of government assistance. This notion that some unemployed could work but choose not to (Howe, 1998) was further underpinned by the Minister's comments that 'there is no right to demand from your fellow Australians that just because you don't want to do a bread delivery or taxi run or a stint as a farmhand that you should therefore be able to rely on your fellow Australian to subsidise you' (Abetz, 2014b). Abetz urged young unemployed people to go to Tasmania and work as fruit pickers, thus advocating low-paid, insecure, seasonal work over being unemployed while seeking local opportunities. These federal policy ideas privilege immediate productivity over all other aspects of life and suggest that unemployed people should be prepared to move anywhere and do anything in order to be economically productive. Abetz further noted that 'It is just not acceptable to have job seekers sitting at home on welfare when employers keep saying they can't find enough workers' (Abetz, 2014a), the implication being that the policy solution to unemployment is one of matching 
supply and demand: that reducing unemployment is simply a matter of matching unemployed people to employment vacancies.

This dominant supply and demand narrative, which implies that some unemployed people are undeserving, lazy and too particular about the work they are prepared to do, has been challenged by researchers and welfare advocacy groups who note that such rhetoric ignores the effects of cycles of disadvantage and the importance of community and family connections. Critics note the tensions between the short-term goal of getting people off of welfare, and the longer term goal of sustainable labour market attachment (Davidson, 2011).

Youth are one cohort who are disadvantaged in the Australian labour market. People from non-English speaking backgrounds, Aboriginal people, people with low levels of formal education, low literacy and numeracy, and people experiencing mental health issues are also disadvantaged (Davidson, 2011; DEEWR, 2011, 2012; Fowkes, 2011). Furthermore, long-term unemployment in itself is a barrier to future employment, as employers value work experience and continuous work history. Job seekers suffer 'scarring' from being unemployed, paying long-term costs financially and in terms of their personal well-being (Layard, Nickell \& Jackman, 1991; McKeeRyan, Song, Wanberg \& Kinicki, 2005). Indeed, once a person has been unemployed for 12 months, their risk of continuing to be unemployed for another is year is around 50 per cent (ACOSS, 2012; DEEWR, 2012).

This paper undertakes an investigation of interventions within programs which self-nominated as being able to provide an account of how their services produce direct or indirect employment and work readiness outcomes for disadvantaged job seekers. We present the practice principles which underpin successful employment and pre-employment programs and services, and discuss how successful unemployment interventions demonstrate a commitment to moving beyond the supply and demand paradigm, wherein a job vacancy plus an unemployed person is construed as a simple arithmetic solution to workforce exclusion.

Qualitative data was gathered from program evaluation reports and semistructured interviews with operational staff and managers at agencies within the national Anglicare network, which was able to provide effective access to a broad sweet of interventions with significant geographical and organisational variation.. The evidence supports a counter narrative to the dominant policy narrative presented above. We propose that for interventions to be successful, they must address the 
whole person as someone with aspirations, preferences and capabilities, and they must respect social and community connections, and build human capital to underpin sustainable outcomes.

\section{Background and literature}

\section{Workforce exclusion in Australia}

In the wake of the global financial crisis, Australia has a lower unemployment rate than many other OECD nations. However, this headline figure does not capture the unequal geographic distribution of unemployment, or that some groups of Australians are more likely to face disadvantage in accessing employment opportunities than others.

Currently, 21.9 per cent of unemployed people are long-term unemployed (twelve months or more) (ABS, 2014). Young people and those who have not completed Year 12 are disproportionally represented in these statistics (ABS, 2011). Despite the comparatively low unemployment levels, Australia has one of the highest rates of jobless families in the OECD (Productivity Commission, 2014), with 1.3 million jobless families (ABS, 2012). This is highly significant, given that experiencing social disadvantage at school age has been shown to perpetuate disadvantage in later life in terms of lower earnings, higher levels of employment insecurity, and poorer health and well-being outcomes (Lamb \& Rice, 2008).

As Cortis, Bullen and Hamilton (2013) note, even when disadvantaged job seekers do access employment opportunities, their transition from welfare to work is rarely sustained over the long-term. Instead, they argue that job seekers typically move between unemployment and jobs with low skills requirements, poor pay, fluctuating or a low number of hours, and few options to develop their skills in order to gain more secure, better paying job roles (Chigavazira, Bowman, \& Scutella, 2013; Wilkins, Warren, Hahn, \& Houng, 2011; Independent Inquiry into Insecure Work in Australia, 2012). Cortis et al. (2013) further note that people cycling back and forth between unemployment and poor quality employment has been associated with poor mental and physical health (Butterworth et al., 2011; McKee-Ryan et al., 2005), which is a hidden story beneath headline unemployment statistics. 


\section{The dominant 'work first' narrative}

Davidson (2011) notes that there are two dominant approaches to engaging with unemployed people. One he refers to as the 'human capital' approach, and the other as the 'work first' approach. The human capital approach emphasises capacity building, while the work first approach emphasises intensive and immediate job searching (Bruttel \& Sol, 2006; Loedemle \& Trickey, 2001), sometimes with a degree of training.

The introduction of the Job Network in Australia in 1998 saw a move away from the human capital approach in favour of the work first approach (Davidson, 2011). The Active Participation model was introduced with Employment Services Contract 3 (2003-2006), which incorporated the concept of mutual obligation, whereby job seekers were required to meet their obligations through participation in employment, training or 'work for the dole' to maintain eligibility for welfare payments (Davidson, 2011). These changes marked a broader neo-liberal shift towards a focus on coupling rights to individual responsibility (Waring, Ostenfeld, Lewer, \& Burgess, 2001). In 2009, the scrapping of the Job Network and introduction of Job Services Australia saw a reduction in the overall budget available to assist unemployed people into employment, as well as a move to a more punitive approach, with increased penalties for non-compliance with participation requirements (Considine, Lewis, \& O'Sulliavan, 2011; Davidson, 2011; Davidson \& Whiteford, 2011). The reduced funding available for job seekers has increased the focus on cheaper intensive job seeking support, and away from more expensive investments in human capital development. These changes have been accompanied by a fee structure for employment service providers that encourages the pursuit of short-term employment outcomes (Davidson, 2011).

The federal government has promoted work for the dole participation as a path to skills development and employment. However, research by Borland and Tseng (2011) demonstrates that work for the dole programs reduce employment outcomes, in large part because they reduce the time available for active job seeking. Furthermore, the Government's financial incentives to workers who relocate to seek work have been shown to have little impact on reducing jobless numbers. Even when there are employment opportunities at the destination end of a relocation, lack of support and lack of social network and community connections can cause the relocation to ultimately fail (Productivity Commission, 2014). 
The 'earn or learn' focus proposed in recent federal budgets has also been demonstrated to have further negative consequences for unemployed people. Welfare advocates have been critical of 'training churn', whereby unemployed people are encouraged to attend funded training programs without consideration of their work preferences or suitability for the work (Chigavazira et al., 2013; Brotherhood of St. Lawrence, 2011). This has resulted in low levels of conversion to employment outcomes. The Brotherhood of St. Lawrence (2011) identified that 44 per cent of their unemployed clients had obtained two or more qualifications in the previous five years (p. 25). Notably, funded training for job seekers is typically for industries with high rates of casualisation and employment insecurity so, even if job seekers are successful in completing training and gaining employment, it may not provide them with long-term economic stability.

A further criticism levelled at the work first approach is that it assumes a level playing field, whereby all unemployed people can obtain work if they are incentivised to do so. In adopting this stance, work first approaches ignore social disadvantage and multiple barriers to employment faced by the most disadvantaged job seekers. They also ignore the evidence that factors associated with social disadvantage also affect job seekers' ability to retain employment (Cortis et al., 2013; Murphy, Murray, Chalmers, Martin, \& Marston, 2011). Not only this, but the approach focuses exclusively on the supply end of the supply and demand equation and ignores specifics, such as many job seekers' need for entry-level position (Cull, 2011).

The dominant work first narrative, with its focus on finding work or ad hoc training exercises, rather than building appropriate skills and capabilities to find and sustain work for the long-term, has been challenged by researchers and advocacy groups. In the next section, we present this critique, and an alternative view of unemployment services and interventions. We also examine the best practice principles for achieving employment pathways which have been identified by previous research.

\section{An alternative narrative and best practice principles}

To counter the work first approach, critics have argued for a 'life first' approach (Dean, 2003) that firstly acknowledges the considerable barriers which unemployed people face in finding pathways into employment, and secondly that puts multifacetted interventions in place to build skills and capacity to achieve sustainable 
outcomes. The former Australian Social Inclusion Board identified four key elements for effective service models, being sustainability, individualised approaches, incremental progression into employment, and accessible services (Australian Social Inclusion Board, 2011). The Australian Social Inclusion Board argued that how people are treated by service providers is important, and that barriers to employment need to be addressed alongside skills development and job seeking to break the cycles of disadvantage (Australian Social Inclusion Board, 2011).

Perkins and Scutella (2008) identify that the most effective employment programs use a case management model, provide post-employment support, have low caseloads and provide tailoring of services based on individual need. Effective programs also have strong links with local employers and other support services, and focus on placing people in quality jobs with good employment conditions.

Cortis et al. (2013) also highlight the importance of post-placement support, citing American evidence that long-term employment support (3-5 years) is advantageous in retaining disadvantaged workers. Such support includes job coaching, mentoring, peer support, personal development, and career guidance (Hendra et al., 2010; Hershey \& Pavetti, 1997; Kellard, Adelman, Cebulla, \& Heaver, 2002). Cortis et al. (2013) also note that job seekers often lack an understanding of the work environment. For example, job seekers who are not acculturated to the workforce may not understand the importance of getting to work on time, of keeping the employer informed if they are unable to attend work, or how to comply with basic policies and procedures, such as those around occupational health and safety. They also identify that a lack of workplace knowledge can lead to assumptions by employers that recruits lack work ethic or are disinterested in work, increasing the risk of disadvantaged workers being dismissed (Cortis et al., 2013). Yet workers often lack this knowledge due to unfamiliarity with workplace environments as a result of being out of work for extended periods, or as a result of coming from an inter-generationally unemployed family.

A life first approach to unemployment interventions shifts the 'unemployment narrative' away from blaming job seekers for their dependence on welfare and lack of work readiness. Instead, this approach acknowledges the effects of disadvantage and the often multiple barriers to employment faced by disadvantaged job seekers. The approach advocates for investment in human capital and engagement with job seekers and employers to create opportunities. It acknowledges the capacities of 
workers, their hopes and preferences, and that people have important attachments to their families and local communities which do not always make relocating for work practical, desirable or sustainable.

The current research engages with this debate by undertaking an investigation of employment and pre-employment programs, along with programs which assist in unemployment intervention without having employment as a sole and specific final objective.

\section{Method}

\section{Methodological approach}

This research adopted a qualitative approach to the investigation of the research question, what service delivery factors or approaches best support employment pathways for some of Australia's most disadvantaged job seekers? The qualitative approach is recognised for its ability to elicit in-depth, complex and subjective data from small sample groups, though a limitation of such an approach is the ability of such methods to provide representative data (Neuman, 2000; Sarantakos, 1998). However, this limitation was not a significant concern in the current research, given that the focus was on identifying best practice and innovation rather than determining the norm.

Data was gathered from semi-structured telephone interviews as well as internal reports of evaluations for some of the 14 programs included in this research. The semi-structured interviews used broad, open-ended questions to prompt conversation and allowed for interesting avenues of investigation to be pursued with follow up questions. Interviews were audio recorded with the permission of participants. The evaluation reports were analysed and data was extracted which corresponded with the topics covered under the interview schedule in order to generate comparative data. All data from interviews and the evaluation reports was imported into NVivo to support the thematic analysis. The analysis used a combination of a priori codes (Crabtree \& Miller, 1999) generated from the literature review and open coding to allow new themes to emerge from the data. Key quotes from the interviews and other sources were identified to best illustrate the identified themes. 
This research was approved by the Flinders University Social and Behavioural Research Ethics Committee.

\section{The programs}

The programs included in this research were operated by agencies within the national Anglicare network. The Anglicare network is one of the largest providers of social and community services in Australia, and was able to provide effective access to a broad suite of interventions with significant geographical and organisational variation. The size, broad service scope, agency diversity and geographical presence of the Anglicare network gave the research a sound basis for exploring key innovations in building work readiness and facilitating employment outcomes. The scope of the programs included in the research allowed for a broad determination of what service delivery factors were effective in supporting the work participation of disadvantaged client groups.

The 14 programs included are aimed at a range of target client groups including youth, Aboriginal people, women, migrants and refugees, people from nonEnglish speaking backgrounds, the inter-generationally unemployed, and people with health conditions and disabilities. More general programs aimed at disadvantaged job seekers and the long-term unemployed are also represented. The programs are located across five states and territories, in metropolitan and rural locations.

\section{Participants}

Interviewees from programs which self-identified as producing workforce inclusion outcomes were recruited via an email invitation from Anglicare Australia's CEO, following which respondents self-nominated to participate in the research. Some participants were operational staff and others were managers. An Information Sheet was provided to all participants and formal written consent obtained prior to each interview commencing. Overall, 11 interviews were conducted with operational managers and frontline staff working within the nominated programs, lasting an average of 25 minutes.

In addition, eight evaluations reports were included in the analysis. Five of these related to programs that the self-nominated participants were employed on. The analysis of three programs therefore relied on an evaluation report only, five 
programs on both interview and report, and the remaining six programs interview only (14 programs in total).

\section{Results}

Of the 14 programs included in this research, three primarily had an education focus, seven had an employment focus and four programs had a narrower focus, assisting clients with specific barriers to employment. The programs therefore assisted disadvantaged job seekers either directly and indirectly in building work readiness. Programs differed on target demographics, metropolitan vs. rural location, duration of program, and the extent to which programs were structured.

Though program workers talked about 'work readiness', they did not imply that all barriers to employment had to be addressed for someone to be considered work ready. Rather, this term reflected that material needs had been met, allowing the unemployed person to start to consider their future pathways into employment, while other perhaps less pressing barriers were being addressed the same time. Some programs did require clients to be more 'work ready' than others due to the nature of additional supports their programs could offer.

We draw on our qualitative research to detail the key themes that emerged from the thematic analysis of strategies that work to assist clients experiencing workforce exclusion. The themes are grouped under two broad headings of 1 ) acknowledging the person at the centre of workforce exclusion, and 2) acknowledging the circumstances which surround the person.

\section{Acknowledging the person at the centre of workforce exclusion}

This group of themes focuses on the person and acknowledging them, not just as someone with barriers, problems and issues, but as someone with strengths, aspirations and something to offer their community as well as a future employer. Overwhelmingly, clients were thought of as active agents in navigating their pathway into employment, with support. Programs noted that pathways are not necessarily linear and that they can include trying out different education or employment options, changing direction, and accessing services again after a period in education or employment. 


\section{Acknowledge aspirations and strengths}

Counter to the dominant narrative that job seekers are 'leaners' or lacking in motivation or ambition, most programs stressed the importance of identifying and acknowledging the aspirations of clients. In two examples from the interviews, clients were supported to follow their musical ambitions. In one program supporting job seekers with chronic health conditions, a young man was encouraged not to dismiss music as an avenue for future employment. The program workers supported him to apply for a music course to develop his talents further. Similarly, a client in a youth education service was encouraged to pursue his musical talents as an employment pathway with great success, as the program worker notes: '[He] has released a single with Paul Kelly and regularly performs music in clubs around Melbourne' (Interview 3).

Clients in this and other youth programs included in this research were encouraged to create a 'personal vision' or an action plan, and to engage in goal setting to assist them in achieving financial and personal independence. Interviewee 3 noted that staff were not called 'case workers', but rather 'youth development workers', to emphasise their role in seeking out, encouraging and developing talent, including leadership. In a micro business program, migrant and refugee women came with ideas for establishing their own small business. This program provided coaches and trainers who were careful not to presume what clients' aspirations or needs were, but rather let the client determine their own direction with training, support and mentoring. The concept that clients are the active agents in creating their own pathways, with programs and services there to support the process, was repeated in many of the interviews and evaluation reports included in this research. The acknowledgement of aspirations and agency aligns with the strengths-based approach that underpins many of the programs. This approach emphasises the positive in a job seeker rather than focusing on deficiencies or 'problems' (Rothman, 1994; Weick, 1983; Weick \& Pope, 1988).

Several interviewees noted the pointlessness of forcing clients down unsuitable pathways and were critical of job services agencies who they identified from client feedback as undertaking this practice. One interviewee observed that disadvantaged job seekers who were told they had to attend Certificate 3 courses in Aged Care or Community Services in order to meet their obligations, were often not able to translate these qualifications into employment outcomes. This was a result of 
being ill-equipped for the type of work, uncertain about what the work entailed, or uninterested in the type of work. As one interviewee argued, clients need to be interested in the type of work they are being considered for, or the pathway is unsustainable. Such unsustainable experiences use up job seekers' allocations of training funding, making it difficult to pursue other avenues of employment for which they are more motivated and better suited.

\section{Life first}

The staff of services and programs included in this research acknowledged that addressing complex barriers is vital if clients are ultimately to engage in employment preparation activities. For example, for homeless clients, looking for employment in the immediate term is not something they are likely to have capacity to do, given that they have no way of cleaning their clothes to appear presentable at work, and nowhere safe to sleep. Many of the programs offered case management and advocacy support around complex issues, and were able to refer clients to in-house or other service providers for specialist services, such as psychological and drug and alcohol services.

Many programs delivered a range of interventions and training that focused more broadly on all aspects of job seekers' lives. Though some training aimed to address specific barriers clients face, others focused on building capacity rather than addressing deficits, in areas such as depression management; communication skills; positive parenting; sex education and relationships; cooking and nutrition; budgeting skills; computing skills; motivational skills; and interpersonal skills. These training initiatives acknowledge that all aspects of life can impact on a person's ability to gain and sustain employment and be financially independent of welfare support. As one interviewee noted, her program's holistic approach to supporting clients was about breaking cycles of disadvantage:

Our key underlying principle is that we want people to be able to be sustainable. We want to break the cycle of poverty and be able to help people to help themselves. We want to resource people, give them not just solutions for today but the capacity to help themselves in the long-term (Interview 7).

One interviewee (a senior manager) concurred that a holistic approach is required to address long-term disadvantage. He reported that his agency is now 
adopting a broader social inclusion stance to all of their programs, as opposed to an exclusive workforce inclusion focus. This incorporates five outcome measures: education and training; employment; community connection and civic contribution; financial security and literacy; and health and well-being. This holistic framework recognises the whole person and the contribution they can make to their community. It values aspects of disadvantaged people's lives in addition to their employment status.

In another example of a holistic approach, one of the youth programs in the study reported that they had recently supported a young female client to achieve her dream of international travel. In exchange for her round-the-world ticket, she ran activities and study groups for her peers as part of the program's 'something for something' deal. Valuing life experiences, not just work experiences, is important for building independence and other important life skills. These skills and capacities in organisation and planning, financial management, communication, leadership and interpersonal skills are then expected to benefit future education and employment pathways and deliver sustained independence.

\section{Acknowledge differences}

All programs offered some element of tailoring to accommodate individual needs and differences, including even the most structured program. In that program, clients met with a life coach and worked through the 'I am Amazing' program to acknowledge their individuality and previous achievements, and to develop goals for the future. Furthermore, the program trainers assisted clients in addressing barriers, such as mental health issues, with referrals to other services, and by directing clients to additional non-accredited training to address a range of life skills.

At the other end of the program spectrum, a street outreach program aimed at youth was entirely unstructured, with service provision tailored to the individual needs of each client. The frontline interviewee from this program described it as:

Informal, flexible, relational but [also] intentional and deliberate. Not just to be lovey-dovey and warm and fuzzy and friendly ... [but to] bring an attitude of ... how do we move forward? We try and be led by them and what they want ... look at higher needs first ... food, clothing, stable accommodation. We try to 
restore some dignity to them and help them to believe in themselves again and feel valued (Interview 5).

In addition to providing for material needs and supporting clients through crises, the program also addresses clients' physical and mental health needs and assists clients with access to educational and employment opportunities.

These two programs represent opposite ends of the structured continuum, but both demonstrate the importance of tailoring programs to meet clients' unique aspirations and needs. Many of the other programs also stressed the importance of acknowledging difference via individual assessments, service tailoring and ongoing communication with clients.

\section{Acknowledging the circumstances which surround the person}

This group of themes focuses on the circumstances that surround a person who is excluded from the workforce. The dominant work first narrative blames job seekers for their own workforce exclusion and attributes them with characteristics such as being lazy, lacking in ambition and trying to avoid work participation in favour of living off of welfare (Howe, 1998). The themes move beyond the focus on the individual, to acknowledge the structural barriers to employment for disadvantaged job seekers. These themes further highlight the contributions a job seeker needs from employment services and employers in order to gain and sustain paid employment.

\section{Connection (social and community)}

Many programs placed high importance on social and community connection. Several programs specifically included community-based projects to assist clients in re-engaging with their community. For example, a program for disadvantaged job seekers who were socially isolated, and who had mental health issues, partnered with a local TAFE in the 'River to Recovery' project. The aim was to build boats and row them $500 \mathrm{~km}$ down the River Murray. The project was declared to be successful on many fronts by the senior manager interviewed. The project assisted clients in overcoming social isolation and building interpersonal and team-based working skills:

People became more connected to their community through this group, they became more connected to TAFE ... For some of those participants, this has 
been a spring board to other things...some people are going back to education, some people have become more involved in advocacy issues (Interview 4).

The partnership with TAFE resulted in some participants reconnecting with education after working alongside TAFE staff throughout the project. In addition, the confidence building aspect of the project led some of the program participants to become more involved in mental health advocacy.

Another program, aimed at migrants and refugees, used social capital as part of their program logic, recognising the importance of assisting clients to build networks and relationships with people in their community, as this can be an important means by which job seekers identify employment opportunities. In a rural based program, an employment preparation and accredited learning program also recognised the benefit of bringing people in the community together. They ran a community café where people could have a free coffee and talk with volunteers. The program also ran a community garden where people could build skills and relationships as well as make a positive contribution to the physical environment of their community.

\section{Quality of employment}

As highlighted in the literature, the dominant supply and demand narrative, with its simple work first focus, employs a numerical simplicity which ignores the lack of entry-level positions for young people and the lack of willingness on the part of employers to take on young people, the socially disadvantaged, and long-term unemployed (Cull, 2011). Employers typically consider such job applicants as 'high risk', and may be reluctant to provide opportunities to such job seekers. This results in socially disadvantaged job seekers engaging in periods of low quality, highly precarious employment that may not provide them with regular or sufficient hours, or with sustainable employment (Cortis et al., 2013).

Furthermore, employers do not always do the right thing by their workers. As a result, obtaining employment is no guarantee of stability, or of a secure attachment to the workforce. In an example from the street outreach program, a young female participant became the first person in her family to finish year 12, after which she secured an office-based entry-level role. However, two years later, the employer was 
failing to pay her at the appropriate level (with no pay rise in two years) and there had also been interpersonal problems in the workplace. These problems left the young worker frustrated but fearful of seeking alternative employment (Interview 5). This anecdote highlights that not all employment is good employment, and that negative employment experiences can further entrench risks of workforce exclusion.

One program in our study used a labour hire model to help overcome employers' lack of willingness to take a risk on disadvantaged job seekers and secure quality employment for clients. The program was conducted in partnership with a major bank, and resulted in the agency carrying all of the employment risk, as the migrant and refugee clients were employees of the agency during their six month placement. Other employees at the bank received cultural training in order to support the migrant and refugee workers, and the agency provided on-going support throughout the placement for the employer, other employees and those on placement. The work placements acknowledged the existence of a 'productivity gap' at the beginning of the placement but aimed to reduce this over the course of the 6 month intervention. As a result of this labour hire arrangement and support, the agency has built a strong relationship with the employer and 80 per cent of those placed have become employees of the bank. This example demonstrates that disadvantaged job seekers have a lot to offer potential employers if they are provided with quality opportunities, with appropriate support, and with time to master role requitements in a secure, learning environment. Other researchers have called for more partnerships of this kind to create opportunities for disadvantaged job seekers (Borland, 2014).

\section{Sustainability}

Many participants stressed the need for job seekers to be supported once they are placed in employment, which aligns with previous research findings (Cortis et al., 2013; Hendra et al., 2010; Hershey \& Pavetti, 1997; Perkins \& Scutella, 2008). Postplacement support requires the co-operation of the employer and the client's supervisor or manager. Such support needs to be handled sensitively so as not to set the client apart in a negative way. Again, approaches to building capacity and building on strengths are better than approaches that stress what the client is not able to do. Post-placement support offered by programs included in the study was 
not necessarily for a set period of time and was generally envisaged to reduce as clients gained confidence and competence in their new job role.

In an example of the ways in which support can assist disadvantaged job seekers to achieve sustainable outcomes, an asylum seeker and refugee program placed four job seekers at a local library. The work placement was for up to 12 months and included ongoing support to assist the job seekers to build capacity. The placement was part of a traineeship to gain a qualification as well as work experience. Furthermore, the work place allowed job seekers to practice their English and engage with their local community, as well as providing exposure to Australian workplace culture, and networks that build opportunities.

In the previously cited migrant and refugee women's micro-business program, clients were provided with ongoing support as they set up and developed their own businesses. Many of the women were also allocated a business mentor. These mentors were managers or businesswomen from their own community. The mentors met with the women regularly and provided their expertise and support as well as additional opportunities for the women to practice their English. These examples illustrate the practice of supporting exits from workforce exclusion, and of creating the right supports and relationships around a client to sustain an employment placement.

One specific barrier to being able to sustain employment that came up many times in both the interviews and the reports reviewed was transportation. Disadvantaged job seekers typically rely on public transport which may be limited in rural areas or not run at compatible times with hours of employment. This was particularly the case with care, cleaning, retail and hospitality work that may require weekend and atypical hours of employment. Some programs addressed the issue of transportation by paying for bus tickets, while others took more comprehensive approaches. A youth program worker reported that they have volunteers who provide their young people with driving experience and support. The program also funds the mandatory two paid lessons with a professional instructor in order to assist program participants with obtaining their driving licenses. In another program, participants who had a job offer could participate in a loan initiative to obtain funds to buy a car. Such support initiatives help disadvantaged job seekers overcome a major hurdle to sustainable employment. These initiatives recognise that sustainable workforce inclusion and attachment is about much more than 'getting a job'. 


\section{Discussion}

\section{Summary of findings}

The programs included in this research make significant contributions to building work readiness and achieving education and employment outcomes for disadvantaged job seekers. The programs differ on many levels, but are consistent in recognising the centrality of wrap around support to sustainable employment outcomes.

We have identified that an acknowledgement of the person at the centre of workforce exclusion is essential for effective engagement with disadvantaged job seekers. This means that recognising each person's strengths, preferences, aspirations and support needs is critical. We have also identified that an acknowledgement of the circumstances which surround a workforce excluded person cannot be ignored, as a simple 'work first' approach can lead to unsustainable outcomes. Within the programs investigated by this research, disadvantaged job seekers were able to access a broad array of supports and referrals to other services to address their barriers. Many of these services recognised that social connection and community participation are important for overcoming the social exclusion that often goes hand in hand with being unemployed and disadvantaged in Australia. Importantly, we identify that quality employment and sustainable attachment to the paid labour market requires an investment in building relationships with local employers, and in longer-term support as people consolidate their attachment to the workforce.

\section{Conclusions - implications for policy and practice}

The themes identified in this research challenge dominant narratives about unemployment and workforce exclusion. Such narratives, which cast job seekers as unmotivated, lazy and too fussy are shown to be ill-conceived by the evidence from this study, and by recent literature.

Job seekers have aspirations and strengths, but they need support to develop these into sustainable employment pathways. A narrow 'job first' focus privileges immediate economic productivity and focuses on short-term outcomes that get job seekers off of welfare at the expense of durable and sustainable change. One interviewee sums up the futility of this approach to unemployment intervention, which 
treats workforce exclusion as a simple arithmetic problem of supply and demand, and of a willingness to accept whatever is supplied:

The supply and demand argument is an interesting one as I can't count the number of anecdotes I have heard: 'I don't know why people aren't going for jobs. I saw a sign up at my local Bunnings .... why are they just going for that job?' But it's not as straight forward as 'oh...there is a hole, let us put that person in that hole'. Employers might get hundreds of applicants ... they screen people out ... I hear stories of young people submitting over a hundred applications and not even getting an interview ... that breeds its own despair (Interview 8).

We have identified that approaches to intervening in unemployment and workforce exclusion need to acknowledge both the workforce excluded person and their circumstances. They need to account for the complexity of joblessness. In practical terms, this means approaching job seekers with a partnership in mind, and building relationships where unemployed people's strengths and aspirations are acknowledged, respected and used to determine future pathways.

We also acknowledge that social exclusion often goes hand in hand with workforce exclusion and have highlighted different programs' efforts to combine breaking down social exclusion with the process of creating pathways to employment. More partnerships with community groups and TAFEs will assist disadvantaged job seekers to build both work and social capacity. The importance of this should not be downplayed, given that employers expect applicants to have interpersonal and team-working abilities in order to perform many job tasks and responsibilities.

Our research highlights the significant successes of supported work placements, especially when they incorporate training for a meaningful qualification and the opportunity to gain ongoing employment, such as in the bank-agency partnership. Notably, this partnership was achieved on a labour hire model whereby the employer was sheltered from employment risk until the agency had supported job seeker capacity sufficiently to reduce performance gaps. Though such a model inevitably requires higher levels of investment and employer support, the conversion rate to employment in jobs with good working conditions was significant in the model 
which we investigated. Other training needs to be more strongly linked to genuine employment opportunities if such initiatives are not to be mere exercises in meeting mutual obligation requirements. Work placements during training could help disadvantaged job seekers build skills and establish networks to assist them in gaining future employment.

On a practical level, transport remains a major barrier to disadvantaged job seekers who rely on public transport. Getting support to obtain a driving license, such as in the youth program example, and affordable loans to buy a car, are key means by which workers can sustain work attachment. More schemes such as these would support disadvantaged job seekers who lack the funds to achieve car ownership independently, and also open up work options over a broader geographical area than that available to people relying on public transport.

All of the strategies highlighted here require more investment and longer-term support for the most disadvantaged job seekers if those job seekers are to move away from short-term employment interspersed with periods of unemployment. The logic of the life first interventions cited in this research appreciates the complexity of workforce exclusion, and the capacities of unemployed people. It recognises the necessity of focussing on the person in a positive, partnership-orientated and capacity building way, and of acknowledging the circumstances which surround the person. It recognises that quality services and quality jobs are at the heart of durable employment outcomes. This recognition, and this move beyond 'work first' solutions to unemployment which operate on the premise of simply matching labour force demand and supply, is a constructive step away from simple analyses of unemployment being a product of indolence. It is a step towards appreciating and harnessing the ambitions of workforce excluded people.

\section{Acknowledgements}

This research was commissioned by Anglicare Australia.

\section{References}

Abetz, E. (2014a, May 26). Young and without work? Take up fruit picking, says Liberal Senator Eric Abetz. Sydney Morning Herald (online). Retrieved from http://www.theland.com.au/news/agriculture/general/news/get-a-haircut-andget-a-farm-job/2699725.aspx 
Abetz, E. (2014b, June 6). Employment Minister Eric Abetz urges young jobless Tasmanians to embrace work for the dole scheme. Mercury News. Retrieved from http://www.themercury.com.au/news/tasmania/employment-minister-ericabetz-urges-young-jobless-tasmanians-to-embrace-work-for-the-dolescheme/story-fnj4f7k1-1226945396910

ACOSS. (2012). Submission to senate inquiry into the adequacy of allowance payments. Australian Council of Social Service.

Australian Bureau of Statistics. (2011). Australian social trends-long term unemployment (Catalogue No. 4102.0). Retrieved from http://www.abs.gov.au/AUSSTATS/abs@.nsf/Lookup/4102.0Main+Features2 $\underline{0 \text { Sep }+2011}$

Australian Bureau of Statistics. (2012). Labour force, Australia: Labour force status and other characteristics of families (Catalogue No. 6224.0.55.001). Retrieved from http://www.abs.gov.au/AUSSTATS/abs@.nsf/

Australian Bureau of Statistics. (2015). Labour force (Catalogue No. 6202.0). Retrieved from http://www.abs.gov.au/ausstats/abs@.nst/mf/6202.0

Australian Bureau of Statistics. (2014). Labour force, Australia, detailed (Catalogue No.6291.0.55.001). Retrieved from http://www.abs.gov.au/ausstats/abs@.nst/mf/6291.0.55.001

Australian Social Inclusion Board. (2011). Breaking cycles of disadvantage. Department of the Prime Minister and Cabinet, Australian Government.

Borland, J., \& Tseng, Y. (2011). Does 'work for the dole' work? An Australian perspective on work experience programmes. Applied Economics, 43(28), 4353-4368.

Borland, J. (2014). The work/welfare nexus. The Future of Welfare Conference, 3031 October, Melbourne.

Brotherhood of St. Lawrence. (2011). Decent sustainable work for all in a global economy: Submission to the Independent Inquiry into insecure work in Australia. Brotherhood of St. Lawrence.

Brotherhood of St. Lawrence. (2014). On the treadmill: young and long-term unemployed in Australia. Brotherhood of St. Lawrence.

Bruttel, O., \& Sol, E. (2006). Work first as a European model. Policy and Politics, 34, 69-89.

Butterworth, P., Leach, L., Rodgers, B., Broom, D., Olesen, S., \& Strazdins, L. (2011). Psychosocial job adversity and health in Australia: analysis of data from the HILDA Survey. Australian and New Zealand Journal of Public Health, 35(6), 564-571.

Chigavazira, A., Bowman, D., \& Scutella, R. (2013). Job retention and advancement of disadvantaged jobseekers: a synthesis of findings (Vol. August 2013). University of Melbourne (Faculty of Business and Economics).

Considine, M., Lewis, J. M., \& O'Sullivan, S. (2011). Quasi-markets and service delivery flexibility following a decade of employment assistance reform in Australia. Journal of Social Policy, 40(4), 811-733.

Cortis, N., Bullen, J., \& Hamilton, M. (2013). Sustaining transitions from welfare to work: the perceptions of employers and employment service providers. Australian Journal of Social Issues, 48(3), 363-384.

Crabtree, B., \& Miller, W. (1999). A template approach to text analysis: Developing and using codebooks. In B. Crabtree \& W. Miller (Eds.), Doing qualitative research (pp. 163-177). Newbury Park, CA: Sage. 
Cull, E. (2011). Finding the right track: a snapshot study of young people's experiences looking for work with Job Services Australia, Melbourne City Mission, Melbourne. Department of Education Employment and Workplace Relations.

Davidson, P. (2011). Did 'work first' work? The role of employment assistance programs in reducing long-term unemployment in Australia (1990-2008). Australian Bulletin of Labour, 37(1), 51-96.

Davidson, P., \& Whiteford, P. (2011). Activation policies in Australia: background report for OECD review of activation policies in Australia. Paris: Organisation for Economic Cooperation and Development.

Dean, H. (2003). Re-conceptualising welfare-to-work for people with multiple problems and needs. Journal of Social Policy, 32, 441-59.

DEEWR (Department of Education Employment and Workplace Relations). (2011). Labour Market Assistance Outcomes. Canberra, DEEWR.

DEEWR (Department of Education Employment and Workplace Relations). (2012) 'Submission to Senate Inquiry into the Adequacy of Allowance payments'. Canberra, DEEWR.

Department of Human Services. (2014). Budget 2014-15: Stronger participation incentives for job seekers under 30. Retrieved from http://www.humanservices.gov.au/corporate/publications-andresources/budget/1415/measures/job-seekers/64-90066

Fowkes, L. (2011). Rethinking Australia's employment services, Perspectives. Whitlam Institute: University of Western Sydney.

Hendra, R., Dillman, K., Hamilton, G., Lundquist, E., Martinson, K., \& Wavelet, M. (2010). How effective are different approaches aiming to increase employment retention and advancement? Final impacts for twelve models. New York: MDRC.

Hershey, A., \& Pavetti, A. (1997). Turning job finders into job keepers'. The Future of Children, 7(1), 74-86.

Howe, L. (1998). Scrounger, worker, beggarman, cheat: the dynamics of unemployment and the politics of resistance in Belfast. The Journal of the Royal Anthropological Institute, 4(3), 531-550.

Independent Inquiry into Insecure Work in Australia. (2012). Lives on hold: unlocking the potential of Australia's workforce, report of the independent inquiry into insecure work in Australia. Australian Council of Trade Unions.

Kellard, K., Adelman, L., Cebulla, A., \& Heaver, C. (2002). From jobseekers to job keepers: job retention, advancement and the role of in-work support programmes. Department of Work and Pensions. Retrieved from http://research.dwp.gov.uk/asd/asd5/rrep170.pdf

Lamb, S., \& Rice, S. (2008). Effective intervention strategies for students at risk of early leaving: discussion paper. Melbourne: Centre for Post-compulsory Education and Lifelong Learning, University of Melbourne.

Layward, R., Nickell, S., \& Jackman, R. (1991). Unemployment, macroeconomic performance and the labour market. Oxford: Oxford University Press.

Loedemel, I., \& Trickey, H. (2001). An offer you can't refuse. London: Policy Press.

McKee-Ryan, F., Song, Z., Wanberg, C. R., \& Kinicki, A. J. (2005). Psychological and physical well-being during unemployment: a meta-analytic study. Journal of Applied Psychology, 90(1), 53-76.

Murphy, J., Murray, S., Chalmers, J., Martin, S., \& Marston, G. (2011). Half a citizen: life on welfare in Australia. Sydney: Allen \& Unwin. 
Neuman, W. (2000). Social research methods: Qualitative \& quantitative approaches $\left(4^{\text {th }}\right.$ ed.). Boston: Allyn \& Bacon.

Perkins, D., \& Scutella, R. (2008). Improving employment retention and advancement of low-paid workers. Australian Journal of Labour Economics, 11(1), 97-114.

Productivity Commission. (2014). Geographic labour mobility: Research report (April 2014). Australian Government.

Rothman, J. (1994). Practice with highly vulnerable clients. Englewood Cliffs, NJ: Prentice Hall.

Sarantakos, S. (1998). Social research $\left(2^{\text {nd }}\right.$ ed.). South Yarra, Australia: Macmillan Education.

Waring, P., Ostenfeld, S., Lewer, J., \& Burgess, J. (2001). The third way, employment and the workplace in Australia. The Economic and Labour Relations Review, 12(2), 174-192.

Weick, A. (1983). A growth-task model of human development. Social Casework, 64, 131-137.

Weick, A., \& Pope, L. (1988). Knowing what's best: a new look at self-determination. Social Casework, 69, 10-16.

Wilkins, R., Warren, D., Hahn, M., \& Houng, B. (2011). Families, incomes and jobs, Volume 6: a statistical report on Waves 1 to 8 of the Household, Income and Labour Dynamics in Australia Survey, Melbourne Institute of Applied Economic and Social Research, The University of Melbourne.

\section{Biographical notes}

lan Goodwin-Smith is the Director of the Australian Centre for Community Services Research at Flinders University. He has nested research interests in social theory, social policy and social services.

Claire Hutchinson is currently completing her $\mathrm{PhD}$ in Psychology on workplace flexibility. Her other research interests include gender and work, workforce exclusion, occupational health and work-life outcomes. 